\title{
DIÁLOGOS INTERCULTURAIS, ESCOLA E IDENTIDADE ÉTNICA: O Que Revelam Dissertações de Mestres Indígenas em Mato Grosso do Sul?
}

\author{
Thiago Moessa Alves ${ }^{1}$ \\ Klinger Ciríaco ${ }^{2}$
}

\begin{abstract}
RESUMO
Analisamos neste artigo duas narrativas de mestres indígenas em decorrência dos resultados de suas dissertações vinculadas a uma universidade pública. O papel da escola indígena na busca pela ressignificação das identidades étnicas em Mato Grosso do Sul (MS) está no cerne da questão geradora do tema debatido. Para este fim, destacamos o debate a partir das produções científicas de dois colaboradores, bem como por entrevistas concedidas por estes pesquisadores. A perspectiva metodológica de tratamento dos dados é a pesquisa qualitativa em educação de caráter descritivo-analítico. As análises apontaram que a escola é vista pelos sujeitos como uma instituição fundamental aliada à luta por direitos essenciais negados aos povos indígenas, fato emergente e recorrente das narrativas eleitas como objeto de estudo aqui apresentado.
\end{abstract}

Palavras-chave: Interculturalidade. Identidade indígena. Escola indígena. Educação multicultural e bilíngue.

\section{INTERCULTURAL DIALOGUES, SCHOOL AND ETHNIC IDENTITY: WHAT DOES INDIGENOUS MASTERS' DISSERTA- TIONS SHOW IN MATO GROSSO DO SUL?}

\begin{abstract}
It is analyzed in this article two indigenous masters' narratives resulting from their dissertations linked to a public university. At the heart of the issue that generates the theme discussed is the role of the indigenous school in the search for the re-signification of ethnic identities in Mato Grosso do Sul (Brazil). To this end, we highlight the debate based on the scientific productions of two collaborators, as well as interviews given by these researchers. The methodological perspective of data treatment is qualitative research in education in descriptive-analytical type. The analyzes pointed out that the school is seen by the subjects as a fundamental institution allied with the search for essential rights denied to the indigenous peoples, emergent and recurrent fact of the narratives chosen as object of study presented here.
\end{abstract}

Keywords: Interculturality. Indigenous identity. Indigenous school. Multicultural and bilingual education.

RECEBIDO EM: $15 / 2 / 2019$

ACEITO EM: 24/4/2019

\footnotetext{
${ }^{1}$ Doutorando em Educação pela Unesp de Presidente Prudente-SP. Mestre em Letras pela Universidade Federal da Grande Dourados - UFGD - e licenciado em Letras pelas Faculdades Integradas de Naviraí - Finav. t_moessa@ hotmail.com

${ }^{2}$ Professor-adjunto do Departamento de Teorias e Práticas Pedagógicas (DTPP) da Universidade Federal de São Carlos - UFSCar. Doutor e mestre em Educação pela Unesp de Presidente Prudente-SP. Docente permanente do Programa de Pós-Graduação em Educação Matemática do Inma da Universidade Federal de Mato Grosso do Sul - UFMS, Campo Grande. ciriacoklinger@gmail.com
} 
Temos como propósito apresentar resultados de uma investigação, realizada no período de 2011 a 2014, em que se pretendeu compreender o processo da formação da identidade indígena no Mato Grosso do Sul (MS) com base em dissertações produzidas por professores/pesquisadores indígenas - um deles da etnia Kaiowá, o outro Terena bem como em entrevistas realizadas com estes mestres que tiveram seus trabalhos defendidos nos Programas de Pós-Graduação stricto sensu em Letras (PPGL) e em História (PPGH), ambos na Universidade Federal da Grande Dourados (UFGD).

O estudo a que nos referimos foi desenvolvido pelo primeiro autor (ALVES, 2014) ${ }^{3}$ e revisitado teoricamente pelo segundo autor, com base na perspectiva dialógica das possibilidades de inserção da interculturalidade na discussão. Os dados evidenciaram a escola como instituição com papel central na busca pela ressignificação das identidades por parte das comunidades cujos professores têm relação de pertencimento. Busca-se, portanto, no recorte deste artigo, compreender os esforços direcionados à escola para ressignificar a identidade étnica dos sujeitos tanto institucionalmente quanto da comunidade na qual se inserem.

\section{REFERENCIAL TEÓRICO}

De acordo com o Instituto Brasileiro de Geografia e Estatística (IBGE, 2012), em 2010 a população autodeclarada indígena no Brasil ultrapassava 890.000 pessoas. Deste quantitativo, aproximadamente $36,2 \%$ reside em área urbana, o que corresponde a um número próximo a 380.000 indígenas vivendo nas cidades. Com o crescente processo de migração de famílias indígenas, há um aumento considerável no atendimento dessa população nas escolas públicas urbanas, o que demanda a proposição de políticas públicas que atentem e atendam às diferenças socioculturais e linguísticas dos povos indígenas nas aldeias e fora delas (MELO et al., 2018).

Mangolim (1997) explica que os indígenas Terena, no Mato Grosso do Sul, estão distribuídos nos municípios de Anastácio, Aquidauana, Miranda, Dois Irmãos do Buriti, Sidrolândia, Rochedo, Nioaque e Dourados. Em outro estudo, o mesmo autor (1993) elucida a cordialidade como estratégia de sobrevivência adotada pelos Terena, fato que os levou a manterem contato aproximado tanto com outros povos indígenas quanto com não indígenas e, por isso, terem adotado práticas culturais de outros povos sem, no entanto, abandonarem elementos profundos que lhes dão coesão como um povo.

Colman (2015, p. 3-4) considera que no Brasil

[...] a população guarani está dividida em três grupos sócio-linguístico-culturais: Ñandeva, Kaiowá e Mbyá; vivem em centenas de aldeias espalhadas por mais de 100 municípios brasileiros, localizados em sete Estados das regiões Centro-Oeste, Sul e Sudeste: Rio Grande do Sul, Santa Catarina, Paraná, São Paulo, Rio de Janeiro, Espírito Santo e Mato Grosso do Sul.

\footnotetext{
${ }^{3}$ Pesquisa orientada professora doutora Maria Ceres Pereira junto ao Programa de Pós-Graduação em Letras da UFGD.t_moessa@hotmail.com
} 
Na conjunta atual, quando do momento da elaboração deste texto, a população Kaiowá e Guarani da região sul do Estado de Mato Grosso do Sul é de 52.000 pessoas (IBGE, 2016). Cavalcante (2013, p. 88) destaca que deste quantitativo “[...] aproximadamente 2.700 vivem em situação de acampamentos à beira de estradas ou em pequenas áreas dentro dos seus antigos territórios, cerca de 38.700 em reservas indígenas criadas pelo SPI [Serviço de Proteção aos Índios] nas décadas de 1910 e 1920, e 11.000 em terras indígenas demarcadas após os anos 1980".

Esses dados são bastante conservadores e não computam grande parte da população indígena que vive em áreas urbanas, o que faz considerar que estimular a população guarani e kaiowá de Mato Grosso do Sul em 60.000 pessoas vivendo em diferentes formas de assentamentos não seja nenhum exagero (CAVALCANTE, 2013, p. 84).

Em um estudo acerca dos processos interculturais e migratórios da população indígena, Melo et al. (2018, p. 1.006) afirmam que entre as hipóteses que se pode levantar para compreender a grande migração de famílias indígenas para o espaço da cidade pode-se apresentar a tese de duas, quais sejam:

[...] 1) A perda do território que se inicia com a chegada da Companhia Matte Larageira no pós-guerra entre a Tríplice Aliança e o Paraguai, primeira frente de expansão econômica na região sul do atual Estado de Mato Grosso do Sul. 2) A intensa participação dos Kaiowá e Guarani [assim como os Terena] nos processos e ciclos produtivos em Mato Grosso do Sul, sendo possível citar o início dessa participação já na exploração da erva-mate nos anos finais do século XIX, depois passando pelos trabalhos de abertura de estradas e formação da estrutura de muitas das atuais fazendas, conjuntamente com a derrubada de mata e o plantio de pastagem, corte de cana-de-açúcar e outras modalidades de trabalho no campo. Até o momento mais contemporâneo, onde atuam como trabalhadores das usinas de cana-de-açúcar e em postos de trabalhos subalternos em meio à população urbana.

Uma questão fulcral, neste ponto, portanto, é a problematização da ideia ainda muito corrente no senso comum de que o contato dos povos indígenas com o não indígena, o uso da Língua Portuguesa, o trânsito na cidade, uso de celulares, o trabalho remunerado, entre outros fatores, descaracteriza a identidade indígena, como se elementos como estes fossem suficientes para determinar os modos de ser indígena.

Com base nesta leitura, parece ser habitual a afirmação de que as identidades étnicas indígenas são condições que precisam de uma compreensão plural. Desse modo, precisamos ter em mente que o contexto escolar é um espaço-tempo de busca pelo território de pertencimento, como também da construção e marca de uma identidade, pela presença de indígenas na rede escolar e, mais tarde, no Ensino Superior, especificamente (MELO et al., 2018). Não resta dúvida de que isso é uma situação complexa, uma vez que o desafio de "[...] um ambiente multicultural redobra as atenções necessárias para que se construa um espaço educacional de diálogo pautado pela interculturalidade" (MELO et. al., 2018, p. 1.008).

Candau (2008), ao escrever sobre interculturalidade, em uma leitura teórica do assunto, considera que esta define-se como um espaço de "multiculturalidade aberto e interativo" (destaque nosso). Em outras palavras, ao pensarmos sobre o papel da escola 
nestes espaços de ir e vir, no choque constante entre o eu e o outro em que os povos indígenas se encontram no Mato Grosso do Sul, é possível afirmar que estamos a falar de uma educação aberta ao exercício de reconhecimento do "outro", "[...] para o diálogo entre diferentes grupos sociais e culturais" (p. 52).

\begin{abstract}
Uma educação para a negociação cultural, que enfrenta os conflitos provocados pela assimetria de poder entre os diferentes grupos socioculturais nas nossas sociedades e é capaz de favorecer a construção de um projeto comum, pelo qual as diferenças sejam dialeticamente integradas. A perspectiva intercultural está orientada à construção de uma sociedade democrática, plural, humana, que articule políticas de igualdade com políticas de identidade (CANDAU, 2008, p. 52).
\end{abstract}

Em síntese, consideramos essa perspectiva teórica indispensável para se realizar um trabalho, desde os primeiros anos de escolarização dos sujeitos até o ingresso no Ensino Superior e na vida acadêmica em programas de Pós-Graduação (Mestrados e Doutorados), com vista ao contexto multicultural que o debate teórico e metodológico da academia pode promover na visão de mundo de uma pessoa. Pretendemos, a partir desses apontamentos teóricos iniciais, compreender os esforços direcionados à escola para ressignificar a identidade étnica dos sujeitos tanto no campo institucional quanto no da comunidade em que se inserem.

\title{
SÍNTESE DOS ASPECTOS METODOLÓGICOS E IDENTIFICAÇÃO DOS PROFESSORES/PESQUISADORES/INDÍGENAS
}

Conforme já mencionado anteriormente, trata-se de um trabalho de pesquisa desenvolvido pelo primeiro autor e que teve a perspectiva teórica revisitada com o objetivo de contribuir para as questões da interculturalidade com o foco na construção das identidades étnicas dos entrevistados.

Neste espaço investigativo, adotamos a pesquisa qualitativa de caráter descritivo-analítico (LÜDKE; ANDRÉ, 1986) em que as dissertações produzidas pelos mestres indígenas e entrevistas que nos concederam foram elementos estruturantes para dar visibilidade à indianidade sul-mato-grossense na produção de seus trabalhos defendidos em programas de Mestrado em uma universidade pública do interior do Estado.

Um deles pertencente à etnia Kaiowá, da Aldeia Bororó em Dourados-MS, cursou Mestrado em Letras na UFGD. O outro é Terena, reside na Aldeia Buriti em Dois Irmãos do Buriti-MS e cursou Mestrado em História na mesma instituição.

\section{O mestre Kaiowá}

É importante lembrar que o mestre Kaiowá é graduado e mestre em Letras, por isso é frequente sua preocupação sobre aspectos linguísticos. A sua dissertação discorre sobre letramento e bilinguismo na aldeia em que vive. $O$ autor faz isso mostrando o papel da Língua Portuguesa e das línguas étnicas na conjuntura da escola atual, bem como evidenciando o desejo de otimizar a relação entre as línguas nas escolas de sua aldeia.

Exemplo disso é o tom crítico que dá no relato sobre como aprendeu a língua Kaiowá: 
[...] na escola tradicional onde estudei, na aldeia, e não era um caso único, a língua indígena era negada. Meus pais também a negaram para mim porque entendiam que ter essa língua causaria transtorno na escola. Tanto meus pais quanto a escola não valorizavam a língua. Eu aprendi a mesma como L2, sempre em situações informais pelo convívio com os falantes da mesma (MACHADO, 2013, p. 12).

Temos nessa narrativa um exemplo sobre como a cultura da Língua Portuguesa oprime outras línguas minoritárias. Há, conforme atesta o autor, variadas situações linguísticas nas aldeias de Dourados: primeiramente, existem aqueles alunos que chegam à escola falando somente as línguas Guarani, Kaiowá ou Terena, dependendo da etnia a qual pertencem; há também aqueles que falam somente a Língua Portuguesa e, por fim, aqueles que falam ambas as línguas. Nesse último conjunto há ainda duas situações, grupos que têm a língua indígena como Língua Materna (LM) e o português como Segunda Língua (L2), ou o contrário.

Ambas essas situações requerem abordagens diferenciadas durante a alfabetização. A inobservância desse contexto linguístico pela escola tem gerado graves problemas educacionais.

[...] os altos índices de reprovação e evasão dos alunos Guarani/Kaiowá eram a desmotivação e desânimo com a prática pedagógica escolar. Quando chegava a época dos encerramentos das aulas, ouvia frases como estas das mães: [...] meu filho reprovou novamente, ele vai sair da escola e ir trabalhar fora, porque já é grande (MACHADO, 2013, p. 12-13).

\section{O mesmo pode ser observado na entrevista:}

Ó que nem o ano passado teve salas aí parece que na Tengatuí [...] que reprovaram $70 \%$. Isso não na alfabetização. São salas do 6. ao 9.o ano, tanto em Língua Portuguesa ou na disciplina de Matemática. Então, você vê? É preocupante [...] (MACHADO, 2013, entrevista).

Nesse ponto, o pesquisador alinha-se a Freinet para propor uma pedagogia que respeite o cenário cultural. Consideramos a proposta de Machado (2013) apropriada ao objeto de estudo do autor, pois esses $70 \%$ revelam, a nosso ver, um problema que remonta a uma série de fatores histórico-sociais, mas queremos destacar aqui a falta de identificação entre a escola e a comunidade na qual está inserida, não apenas na questão do monolinguismo, mas também em relação aos conteúdos ministrados. No caso analisado, ao que tudo indica, podemos tecer uma afirmação de que o modelo da escola inserida na aldeia descrita por Machado (2013) não tem uma identidade indígena, conforme o próprio autor sugere nas entrelinhas, o que acaba por gerar a evasão escolar. Ou seja, apesar de geograficamente a escola pertencer à terra indígena, a organização, as práticas ainda são muito orientadas pelo ambiente externo à aldeia.

Entendemos que para o autor a escola é ainda um agente gerador de crise de identidade: "Para a maioria dos Guarani/Kaiowá, a escola tem pouca importância, não tem muito sentido, uma instituição do não índio que adentrou nas comunidades, roubando-Ihes a cultura e a língua" (MACHADO, 2013, p. 27). Para respaldar sua concepção de escola "alienadora" o autor recorre à opinião dos pais dos alunos. 
"Minha filha foi para a escola e agora não quer ouvir mais meus conselhos. Não sei o que vou fazer". Muitos pais Kaiowá alegam que as instituições de ensino formal roubam a cultura dos jovens e incorpora nestes valores alheios, como a desobediência e a agressividade. Outra fala é de um [...] pai de três adolescentes que estudam na Escola Tengatuí: "Hi [...], agora as crianças foram para a escola e aprendeu de tudo, não quer mais obedecer a gente, quer as coisas, lá ele viu de tudo né, filme, celular, computador, quando chega na casa parece filho de branco, não quer nem mais falar guarani" (MACHADO, 2013, p. 27).

A escola indígena, portanto, ao mesmo tempo em que transmite os conhecimentos científicos da cultura da Língua Portuguesa, deve servir de ponte para o resgate da cultura étnica, mas o que observamos na dissertação analisada é que isso não tem ocorrido, uma vez que a escola tem, em grande medida, se pautado pelo ensino dos saberes não indígenas e que estes passam pela língua. É em Língua Portuguesa que os conhecimentos são apresentados. Os saberes tradicionais indígenas não têm espaço nessa escola. A falta de identificação entre escola e comunidade é então mais uma vez denunciada.

A escola formal acaba ficando com a incumbência de promover os ensinos que a comunidade não repassa mais às crianças e jovens. A instituição deve dialogar com duas culturas, a letrada e a informal. Neste cenário, a escola não possui competências para dialogar com essas duas culturas (MACHADO, 2013, p. 50).

No nosso entendimento, um dos aspectos que dificultam essa ponte entre escola e comunidade é a tradição escolar em priorizar a cultura escrita, enquanto que a cultura indígena é essencialmente oral. Ao adentrar nas aldeias a escola não soube se adequar à nova realidade, um dos fatores que geram os altos índices de reprovação nas escolas indígenas citados pelo mestre indígena. Outro fator relevante a ser destacado é o entendimento de que a escola fora transplantada para o cenário indígena com a forma de ser da escola não indígena porque, naquele contexto, não havia tradicionalmente a escola.

Com efeito, a escola já não estava preparada para ensinar os filhos dos proletários que se matricularam após a "democratização do ensino" na década de 80 , e, quando analisamos o contexto indígena, percebemos que a situação fica ainda mais crítica.

A tão desejada ponte entre a escola e a comunidade indígena certamente perpassa pela valorização da língua e dos saberes indígenas, incluindo nesse cenário a escola bilíngue, que não segrega a língua étnica.

[...] os indígenas são forçados a serem bilíngues (língua indígena/língua portuguesa), até por necessidades de comunicação e de sobrevivência. É importante frisar que servidores públicos não índios que trabalham com essa comunidade, e que não dominam a língua indígena, tanto nas áreas de saúde, educação, agricultura, órgãos como Funasa (Fundação Nacional de Saúde) e Funai (Fundação Nacional do Índio) se comunicam com os indígenas somente na língua vernácula. Nas áreas de saúde e educação o canal comunicativo é bastante crítico. Nos atendimentos públicos de saúde, pela má expressão dos indivíduos indígenas na língua portuguesa que não conseguem transmitir suas ânsias e necessidades corretamente sobre as enfermidades, ocorrem erros graves na indicação de medicamentos por desentendimento linguístico (MACHADO, 2013, p. 19-20). 
Notamos, então, que a importância do trabalho realizado não está limitada ao ambiente escolar, mas estende-se aos variados aspectos que assumem a vida social tanto dentro da reserva quanto fora dela. Da mesma forma, é notável também a consciência de que a escola é um aparelho ideológico a serviço das classes dominantes em detrimento da própria ideologia indígena.

[...] a escola brasileira entrou na aldeia não para formar sujeitos críticos e sim para alienar sujeitos, para ser sujeitos alienados. Se você começar a trabalhar aqui ó. Essas terras aqui eram indígenas. Esses dias passou um cara aqui, nós conversamos com o rapaz. Óh, [...], o curral de aram era deixapirá. Aqui, perto da UFGD era assim. Ali era assim. Foi colocando os nomes. E se você trabalhar isso na escola vai abrir o horizonte dos meninos. E vai dizendo que essas terras eram nossas. Nós não vamos invadir, nós vamos retomar. E a escola quer isso? Não quer! Eu falo da escola como uma instituição pública do governo (MACHADO, 2013, entrevista).

Nesse sentido, alinhamos a excerto em tela, para além do pensamento freinetiano declarado pelo estudioso, ao pensamento freiriano, pois ambos reivindicam o fim de desigualdades sociais por meio do pensamento crítico e de ações de luta por direitos e resistência à opressão (FREIRE, 1987). Alinhamos também ao pensamento althusseriano a respeito dos aparelhos ideológicos do Estado.

Althusser (1985) assevera que na teoria marxista os aparelhos de Estado servem para assegurar as condições de produção, que, por sua vez, exigem a submissão de toda a sociedade às ideologias das classes dominantes. Instituições como o exército, a polícia, os tribunais, as prisões, etc., são considerados no marxismo como aparelhos de Estado.

Ao observar que esses aparelhos funcionam com base na violência, Althusser denomina-os de Aparelhos Repressivos do Estado (ARE), e os diferencia do que nomeia de Aparelhos Ideológicos do Estado (AIE), que funcionam basicamente pela ideologia. São eles: religioso, escolar, de informação, o cultural, etc.

Desta forma, a Escola, as Igrejas "moldam" por métodos próprios de sansões, exclusões, seleção, etc... não apenas seus funcionários mas também suas ovelhas. É assim a Família... Assim o aparelho IE cultural (a censura, para mencionar apenas ela), etc. (ALTHUSSER, 1985, p. 70).

Na tese althusseriana a escola transformou-se no principal AIE, uma vez que

[...] se encarrega das crianças de todas as classes sociais desde o maternal, e desde o maternal ela lhes inculca, durante anos, precisamente durante aqueles em que a criança é mais "vulnerável", espremida entre o aparelho de Estado familiar e o aparelho de Estado escolar, os saberes contidos na ideologia dominante (o francês, o cálculo, a história natural, as ciências, a literatura), ou simplesmente a ideologia dominante em estado puro (moral, educação cívica, filosofia). Por volta do $16 .^{\circ}$ ano, uma enorme massa de crianças entra na "produção": são operários, ou os pequenos camponeses. Uma outra parte da juventude escolarizável prossegue: e, seja como for, caminha para os cargos dos pequenos e médios quadros, empregados, funcionários pequenos e médios, pequenos burgueses de todo o tipo. Uma última parcela chega ao final do percurso, seja para cair num semidesemprego intelectual, seja para fornecer além dos "intelectuais do trabalhador coletivo", os 
agentes da exploração (capitalistas, gerentes) os agentes da repressão (militares, policiais, políticos, administradores) e os profissionais da ideologia (padres de toda espécie [...]) (ALTHUSSER, 1985, p. 79).

Quando relacionamos a divisão do trabalho de acordo com os anos de escolaridade apresentados por Althusser com os números de reprovação apontados, constatamos que a tese althusseriana está correta. Corroboramos essa tese também quando percebemos que nenhum dos 15 mil habitantes da reserva indígena de Dourados está empregado no centro comercial da cidade. Percebemos, todavia, que empregos como o de corte de cana é basicamente realizado pela mão de obra indígena. Poucas mulheres indígenas trabalham como domésticas e a maioria em escolas indígenas. Elas não estão atuando nas escolas fora da aldeia apesar de terem formação e muitas terem Especialização. Não vemos indígenas como atendentes na loja solidária do shopping, mesmo que nesta loja os produtos artesanais sejam confeccionados por indígenas.

Percebemos então como os aparelhos ideológicos são eficientes quando afirmam que é preciso estudar para conseguir um bom emprego ao mesmo tempo em que o Estado não proporciona boa educação ou nem mesmo condições para a permanência do estudante indígena na escola. De fato, o sistema escolar realmente destina o jovem indígena a ser operário ou pequeno camponês, como arguiu Althusser. É tudo previamente articulado pela ideologia capitalista, pois é preciso que haja pessoas para ocupar essas funções que a classe dominante descarta, as que não dão lucro.

Com efeito, existe a escola porque existe a fábrica. A escola existe para qualificar o empregado para atuar na linha de produção, para assegurar as condições de produção e, por fim, o capital.

[...] como se dá esta reprodução da qualificação (diversificada) da força de trabaIho no regime capitalista? Ao contrário do que ocorria nas formações sociais escravistas e servis, esta reprodução da qualificação da força de trabalho tende (trata-se de uma lei tendencial) a dar-se não mais no "local de trabalho" (a aprendizagem na própria produção), porém cada vez mais, fora da produção, através do sistema escolar capitalista e de outras instâncias e instituições (ALTHUSSER, 1985, p. 57).

Queremos enfatizar ainda como, segundo Althusser, ocorre o processo de sujeição da classe dominada pela classe dominante:

[...] aprendem-se na escola as regras do bom comportamento, isto é, as conveniências que devem ser observadas por todo agente da divisão do trabalho conforme o posto que ele esteja "destinado" a ocupar; as regras de moral e de consciência cívica e profissional, o que na realidade são regras de respeito à divisão social-técnica do trabalho e, em definitivo, regras da ordem estabelecida pela dominação de classe (ALTHUSSER, 1985, p. 58).

Além de servir como AIE, relacionamos também a escola como uma das instituições que promovem a exclusão de sujeitos da ordem do discurso por meio do sistema de vontade de verdade. A verdade, como teorizou Foucault (2012), é exercida sob pressão e violência, é arbitrada. Cabe à escola, AIE, portanto, difundir a verdade da classe dominante. 
Enfim, esses aspectos teóricos apresentados são facilmente identificáveis na dissertação e entrevista do autor. Da mesma forma, o mestre Kaiowá também demonstra conhecimento a respeito da luta ideológica classista que coloca a sociedade indígena em posição de subalternidade.

\section{O Mestre Terena}

Assim como o pesquisador Kaiowá, o Terena também propõe a construção de uma escola indígena diferenciada não somente no nome, mas que realmente se identifique com a comunidade indígena, respeitando não só a língua, mas também vários outros aspectos socioculturais envolvidos.

A pesquisa do mestre em História, por outro lado, evidencia o papel da memória dos anciões como elemento que a escola deve utilizar para fortificar a identidade indígena. A principal diferenciação requerida pelo autor consubstancia-se na edificação da educação intercultural.

Assim, entende que a escola indígena deve ser

[...] um espaço institucionalizado no qual a história e a cultura indígenas são valorizadas, revitalizadas e ressignificadas, inclusive com a participação de anciões para o ensino da história Terena às gerações mais jovens (OLIVEIRA, 2013, p. 39).

Por outro lado, ao analisar a escola atual, o historiador aponta os conflitos da escola indígena gerados pelo modelo da escola do não índio.

Essa tensão se expressa em vários níveis e dimensões, desde os conflitos com as estruturas das escolas não indígenas relativos ao currículo, à definição dos dias letivos, à atuação de professores não indígenas, à presença de índios e não índios na mesma sala, ao uso de material didático adequado, ao não domínio das línguas indígenas, etc. Muitos gestores continuam atuando dentro de parâmetros e estruturas dos sistemas dominantes como se todos fossem iguais, ou seja, como se todos fossem não índios e assim negando a identidade do outro (OLIVEIRA, 2013, p. 41).

A constante negação da identidade indígena no ambiente escolar fatalmente culmina no enfraquecimento dessa categoria de identidade. Nesse sentido, do mesmo modo que o mestre Kaiowá, também podemos alinhar o pensamento do mestre Terena à teoria althusseriana. Fazemos isso ao compreender que para o mestre Terena a escola tem servido como meio de ocidentalizar o índio.

Nesses mais de 500 anos de colonização europeia, portanto, a instituição escolar esteve presente, para mais ou para menos, na vida de diversos povos indígenas. Inicialmente, ainda nos tempos coloniais, o objetivo era catequizar, civilizar e integrar os indígenas à sociedade dominante, negando suas identidades diferenciadas e impondo-Ihes valores ocidentalizados. Essa educação sempre esteve ancorada na legislação colonialista que, durante séculos, não levou em consideração toda a diversidade sociocultural referente aos povos indígenas (OLIVEIRA, 2013, p. 51).

Constatamos o mesmo neste excerto: 
A escolarização dos Terena, portanto, tornou-se um dos fatores que os levaram à perda de elementos da sua cultura, tradições e língua materna. Isso aconteceu no contexto da educação formal imposta pelo SPI. Isso fazia parte da política indigenista que incentivava a transformação dos indígenas em trabalhadores nacionais (OLIVEIRA, 2013, p. 42-43).

No texto do mestre Terena podemos perceber, portanto, além da escola, o antigo SPI, atual Funai, como um aparelho ideológico de Estado.

Ficou decidido que os índios teriam suas "reservas" delimitadas e controladas por funcionários do governo. Essas reservas sempre foram menores que os territórios anteriormente ocupados por cada nação indígena. E os índios não podiam opinar. Essa proposta de política em relação aos índios começou a ser praticada a partir de 1910, com a criação do então Serviço de Proteção aos Índios e Localização de Trabalhadores Nacionais (SPILTN), posteriormente rebatizado de SPI. Sua finalidade seria implantar, gerir e reproduzir tal forma de poder do Estado, assim o fazendo por meio de técnicas, práticas administrativas, normas e leis constituídas de um modo que o governo pudesse denominar o índio, status que se engendra e transforma ao engendrá-lo.[...]

Os índios "selvagens" eram os alvos principais da ação do SPI, não só por obstaculizarem o avanço das frentes de ocupação no interior do país ou se acharem em guerra contra elas, mas também por oferecerem as melhores oportunidades para o trabalho de civilização nessas áreas. A educação formal adequada, por sua vez, os impediria de se transformarem em indivíduos "cheios de defeitos", como eram percebidos. O SPI deveria monopolizar ao máximo as interações entre indígenas e "civilizados". O destino final da população indígena seria o mercado de trabalho rural, sob a rubrica de trabalhador nacional, sem distintividade étnica e cultural.

O SPI situava-se, pois, entre os diversos aparelhos de poder que, de modo mais geral, faziam dos povos indígenas a matéria de sua incidência, precavendo e controlando conflitos internos, disciplinando-os e delimitando-os, segundo interesses estratégicos e táticos da administração central (OLIVEIRA, 2013, p. 29-30).

É diante dessas observações que propõe a escola indígena diferenciada, ou educação intercultural. Nela não são valorizados somente os conhecimentos dos não índios, tampouco somente aqueles relacionados à comunidade indígena.

A educação intercultural [...] propõe um diálogo entre os diferentes conhecimentos por entender que, dessa forma, é possível uma compreensão mais global, capaz de pensar as diferentes culturas e identidades de forma dinâmica e não determinista, bem como assegurar direitos e cidadania (OLIVEIRA, 2013, p. 42).

Ainda a respeito da construção da educação diferenciada, sustenta

[...] a questão da escola intercultural e bilíngue só ocorrerá de fato quando a pedagogia indígena entrar na escola. [...] não é mais a escola que tenta se adaptar à vida das aldeias, mas é a própria aldeia, com sua língua, seus costumes, sua maneira de ensinar e suas crenças, que passa a fazer parte do cotidiano da escola (OLIVEIRA, 2013, p. 44).

É possível perceber que na Aldeia Buriti, a Escola Municipal Indígena Alexina Rosa Figueiredo está caminhando na direção da conquista da educação intercultural, como mostra o pesquisador: 
A proposta de uma escola indígena diferenciada ainda se apresenta como um desafio a ser vencido pela comunidade indígena de Buriti. Por isso é que buscamos nos anciões as maneiras de ensinar os costumes e crenças da comunidade. Isso tem sido cada vez mais feito no espaço da escola formal e esta proposta vem crescendo cada vez mais na comunidade, uma vez que lideranças e professores abraçam juntos os deveres de manter uma educação de qualidade. Além disso, assim o fazem para manter viva a cultura Terena, cultura esta que no passado foi impedida de ser ensinada na escola implantada pelo SPI, mas que hoje em dia vem sendo cada vez valorizada e revitalizada na escola (OLIVEIRA, 2013, p. 63).

Por ora, o estudioso apresenta as seguintes características da Escola Alexina Rosa Figueiredo.

a. Específica e diferenciada: concebida e planejada como reflexo das aspirações particulares da comunidade da Aldeia Buriti e com autonomia em relação a determinados aspectos que regem o funcionamento e orientação da escola não indígena.

b. Comunitária: conduzida pela comunidade indígena, de acordo com seus projetos, suas concepções e seus princípios. Isto se refere tanto ao currículo quanto aos modos de administrá-la. Inclui liberdade de decisão quanto ao calendário escolar, à pedagogia, aos objetivos, aos conteúdos, aos espaços e momentos utilizados para a educação escolarizada.

c. Intercultural: reconhece, valoriza e mantém a diversidade cultural e linguística; promove uma situação de comunicação entre diferentes experiências socioculturais, linguísticas e históricas, não considerando uma cultura superior à outra; estimula o entendimento e o respeito entre seres humanos de identidades étnicas diferentes, ainda que se reconheça que tais relações vêm ocorrendo historicamente em contextos de desigualdade social e política.

d. Multilíngue: as tradições culturais, os conhecimentos acumulados, a educação das gerações mais novas, as crenças, o pensamento e a prática religiosos, as representações simbólicas, a organização política, os projetos de futuro, enfim, a reprodução sociocultural das sociedades indígenas é, na maioria dos casos, manifestada através do uso de mais de uma língua. Mesmo os povos indígenas que são monolíngues em Língua Portuguesa continuam a usar a língua de seus ancestrais como um símbolo poderoso para onde confluem muitos de seus traços identificatórios, constituindo, assim, um quadro de bilinguismo importante (OLIVEIRA, 2013, p. 61-62).

Os avanços apresentados pela escola indígena têm, aos poucos, assegurado meIhores condições de vida para os Terena da Aldeia Buriti. Paulatinamente, eles têm se apropriado dos bens que o letramento pode oferecer.

[...] o aprendizado dos jovens Terena na escrita e leitura em Português fez a liderança. A partir daí os Terena de Buriti passaram a escrever e a enviar cartas e abaixo-assinados às autoridades governamentais reivindicando as áreas que foram esbulhadas por fazendeiros, com a autorização do governo do então Estado do Mato Grosso (OLIVEIRA, 2013, p. 50). 
Entre os vários avanços conquistados, certamente a luta pela terra tem recebido um reforço expressivo depois que os Terena de Buriti se tornaram sujeitos letrados. É nesse sentido que destacamos o papel da escolarização como mantenedora dos direitos que a sociedade indígena tanto precisa lutar para conquistar.

Apesar de reconhecer que o modelo escolar tradicional tem agido no sentido de enfraquecer a identidade indígena, tornando-se cada vez mais ocidentalizado, submisso e marginalizado, também destaca o modo como a escola intercultural pode ser utilizada como um instrumento de resistência a essas pressões da sociedade externa à aldeia.

Dominar os códigos que regem a sociedade nacional envolvente não significa, bem entendido, simplesmente render-se a eles, mas, acima de tudo, poder negociar a partir deles. É incluindo-se, fazendo-se presentes na história da sociedade nacional, porém sem abandonar seus costumes tradicionais, ou ao menos a maioria deles, que os índios desejam se fazer respeitar pela diferença. Por isso utilizando-se dos mesmos instrumentos característicos da sociedade ocidentalizada: a palavra escrita, o poder do conhecimento universalmente reconhecido, etc. (OLIVEIRA, 2013, p. 50).

Como mostramos na seção que aborda o cenário das aldeias, o pesquisador afirma que restam somente 30/40 anciões falantes da Língua Terena. Diante desse quadro grave de glotofagia, o pesquisador indígena acredita ainda que a escola é a principal instituição responsável pela revitalização da língua, conforme pode ser observado neste diálogo entre o primeiro autor e o mestre Terena.

\section{Primeiro autor}

Mas você fala a língua terena também?

Mestre Terena

Não

Primeiro autor

Nem como segunda língua?

Mestre Terena

Não, nós falamos bem pouco, coisas bem simples.

Primeiro autor

Uma frase ou outra, então?

\section{Mestre Terena}

Sim. Essa geração minha, não falante, se preocupou: como nós vamos trazer de volta? É a escola! É trazer o professor, o ancião para praticar com nossos alunos, para que volte, porque hoje ela é segunda língua na escola. A primeira é o Português.

\section{Primeiro autor}

Mas e na escola vocês têm disciplina de Inglês, ou têm a Língua Terena?

Mestre Terena

Tem a Língua Terena como segunda língua.

\section{Primeiro autor}

E quem ensina?

Mestre Terena

Um professor indígena falante. Isso gera outra briga: hoje as normas de ensino querem um professor habilitado. Como que nós vamos ter um ancião? 


\section{Primeiro autor}

Um ancião formado em Língua Terena? Isso não existe! (risos)

Mestre Terena

Aí eles querem um professor de Linguística para dar aula. Mas como? Se eu não sou falante, eu posso ser formado em Linguística. Como que eu vou dar aula de Língua Terena? No livro igual é no inglês? Isso nós não queremos! Nós queremos trazer o ancião, a pessoa falante, por isso nós estamos brigando pela escola diferenciada (Entrevista).

Fica evidente também no diálogo apresentado os percalços que ainda precisam ser superados para a construção da escola diferenciada. Notamos que as barreiras ainda existentes dizem respeito muito mais aos aspectos externos à aldeia do que internos, uma vez que os professores Terena estão em processo de formação constante.

As conquistas, por outro lado, não virão de fora para dentro, por isso é de suma importância que os Terena continuem se especializando para conseguirem adentrar nas organizações governamentais, como o MEC por exemplo, e assim conquistarem o direito pleno à educação intercultural com a presença das autoridades indígenas, como os anciões guardadores da memória e da Língua Terena.

Destacamos que os Terena mostram sinais de organização nesse sentido, prova disso é terem conseguido eleger o pesquisador aqui citado como vereador no município de Dois Irmão do Buriti.

\section{CONSIDERAÇÕES FINAIS}

Por fim resta reconhecer, portanto, os pesquisadores aqui estudados como intelectuais da educação indígena, uma vez que conseguem perceber o papel da escola indígena na sociedade atual e, subversivamente, propõem a criação de um outro modelo, de uma escola indígena diferenciada, intercultural e bilíngue, que realmente tenha identificação com a comunidade indígena e, acima de tudo, esteja a serviço dela.

Salientamos também o comprometimento e militância dos mestres indígenas com seu povo. No caso do mestre Kaiowá, persiste em seu trabalho e tem organizado seminários nas escolas indígenas para discutir sobre o ensino e o currículo diferenciado, bilíngue, para as escolas. Ambos tiveram suas defesas nas aldeias junto com seu povo, marcando o fechamento de suas formações com temas ligados as suas tradições. Um dos pesquisadores tornou-se vereador a pedido das lideranças que entenderam que alguém com maior formação poderia representá-los com mais competência e, de fato, é dessa forma que vem atuando na Câmara de Vereadores.

A escola indígena, assim como as demais, é, portanto, palco de disputas políticas. Nesse sentido, o acesso à Pós-Graduação stricto sensu por parte de professores indígenas é fundamental, como é possível perceber nos discursos dos mestres indígenas, para garantir que direitos assegurados na Constituição Federal vigente, Lei de Diretrizes e Bases da Educação Nacional em relação à educação indígena bilíngue e multicultural sejam garantidos. O que evidencia a necessidade de instituição de políticas públicas educacionais mais efetivas direcionadas aos povos indígenas em todos os níveis do sistema nacional de educação. 


\section{REFERÊNCIAS}

AGUILERA URQUIZA, A. H.; PRADO, J. H. O impacto do processo de territorialização dos Kaiowá e Guarani no sul de Mato Grosso do Sul. Tellus, ano 15, n. 29, p. 49-71, jul./dez. 2015. Disponível em: http://www. tellus.ucdb.br/index.php/tellus/article/viewFile/358/349. Acesso em: 13 ago. 2018.

ALTHUSSER, L. Aparelhos ideológicos de Estado. 2. ed. Rio de Janeiro: Graal, 1985.ALVES, T. M. A indianidade sul-mato-grossense: análise da construção da identidade em três dissertações de mestres indígenas produzidas em programas de mestrado da UFGD. 2014. 102 f. Dissertação (Mestrado em Letras) - Universidade Federal da Grande Dourados - UFGD. Dourados, MS. Disponível em: http://files.ufgd.edu.br/ arquivos/arquivos/78/MESTRADO-LETRAS/THIAGO\%20MOESSA\%20ALVES.pdf. Acesso em: 30 jan. 2019.

BRASIL. Ministério da Educação. Referencial Curricular Nacional para as Escolas Indígenas. Brasília: MEC, 1998.BRASIL. Ministério da Educação. Resolução CNE/CEB n. 03/1999.

BRASIL. Estatuto da Criança e do Adolescente (ECA). Lei n. 8069/90.

BRASIL. Lei Orgânica da Assistência Social - LOAS (Lei n. 8742/93).

BRASIL. Lei de Diretrizes e Bases da Educação Nacional (LDB n. 9394/96).

CANDAU, V. M. Direitos humanos, educação e interculturalidade: as tensões entre igualdade e diferença. Revista Brasileira de Educação, v. 13, n. 37 jan./abr. 2008. Disponível em: http://www.scielo.br/pdf/rbedu/v13n37/05.pdf. Acesso em: 30 jun. 2018.

CARDOSO DE OLIVEIRA, R. Urbanização e tribalismo: a integração dos índios Terena numa sociedade de classe. Rio de Janeiro: Jorge Zahar, 1968.

CAVALCANTE, T. L. V. Colonialismo, território e territorialidade: a luta pela terra dos Guarani e Kaiowá em Mato Grosso do Sul. 2013. 470f. Tese (Doutorado em História) - Universidade Estadual Paulista Júlio de Mesquita Filho, Faculdade de Ciências e Letras de Assis, 2013. Disponível em: http://hdl.handle. net/11449/106620. Acesso em: 2 ago. 2018.

COLMAN, R. S. Guarani retã e mobilidade espacial guarani: belas caminhadas e processo de expulsão no território guarani. 2015. 240f. Tese (Doutorado em Demografia) - Universidade Estadual de Campinas, Campinas: Unicamp. Disponível em: http://repositorio.unicamp.br/bitstream/REPOSIP/281217/1/Colman_RosaSebastiana_D.pdf. Acesso em: 9 ago. 2018.

FERREIRA, E. M. L. A participação dos índios Kaiowá e Guarani como trabalhadores nos ervais da Companhia Matte Laranjeira (1902-1952). 2007. 111f. Dissertação (Mestrado em História) - Universidade Federal da Grande Dourados - UFGD. Disponível em: https://tede.ufgd.edu.br/jspui/bitstream/tede/244/1/ EvaMariaLFerreira.pdf. Acesso em: 29 jul. 2018.

FOUCAULT, M. A ordem do discurso: aula inaugural no Collège de France, pronunciada em 2 de dezembro de 1970. Trad. Laura Fraga de Almeida Sampaio. 22. ed. São Paulo: Loyola, 2012.

FREIRE, P. Pedagogia do oprimido. 17. ed. Rio de Janeiro: Paz e Terra, 1987.

IBGE. Instituto Brasileiro de Geografia e Estatística. Censo Demográfico 2012. Características da população e dos domicílios: resultados do universo brasileiro. 2012. Acompanha 1 CD-ROM. Disponível em: https://ww2.ibge.gov.br/home/estatistica/populacao/estimativa2012/default.shtm. Acesso em: 15 dez. 2018.

IBGE. Instituto Brasileiro de Geografia e Estatística. Censo Demográfico 2016. Panorama da população de Mato Grosso do Sul. 2016. Acompanha 1 CD-ROM. Disponível em: https://cidades.ibge.gov.br/brasil/ms/ panorama. Acesso em: 15 dez. 2018.

LÜDKE, M.; ANDRÉ, M. E. D. A. Pesquisa em educação: abordagens qualitativas. São Paulo: E.P.U, 1986. MACHADO, J. Bi-alfabetização e letramento com adultos em Guarani/Português: é possível? Um estudo etnográfico e valorização do Tetã Guarani. 2013. 105f. Dissertação (Mestrado) - Faculdade de Comunicação, Artes e Letras, Universidade Federal da Grande Dourados, UFGD, Dourados, MS, 2013.MANGOLIM, O. Espaço e vida dos índios Terena na Aldeia Limão Verde. Série-Estudos: Periódico do Programa de Pós-Graduação em Educação da UCDB, n. 5, ago. 1997. p. 123-162. Disponível em: http://www.serie-estudos. ucdb.br/index.php/serie-estudos/article/view/642/529. Acesso em: 30 ago. 2018.

MANGOLIM, O. Povos indígenas no Mato Grosso do Sul: viveremos por mais 500 anos. Campo Grande, MS: Conselho Indigenista Missionário Regional de Mato Grosso do Sul, 1993. Disponível em: https://acervo.socioambiental.org/acervo/livros/povos-indigenas-no-mato-grosso-do-sul-viveremos-por-mais-500-anos. Acesso em: 10 jan. 2019.

MELO, J. G. Identidades fluidas: ser e perceber-se como Baré (Aruak) na Manaus Contemporânea. 2009. 225f. Tese (Doutorado em Antropologia) - Universidade de Brasília, Brasília, 2009. Disponível em: http:// repositorio.unb.br/bitstream/10482/4722/1/2009_JulianaGoncalvesMelo.pdf. Acesso em: 5 ago. 2018. 


\section{\&Eđuntextô}

Diálogos Interculturais, Escola e Identidade Étnica:

MELO, R. da C.; PRADO, J. H.; CIRÍACO, K. T.; LOPES, B. G.; SANTINO, F. S. Interculturalidade na Educação Infantil: a relação da criança indígena com o contexto educacional urbano. In: JORNADA NACIONAL DE EDUCAÇÃO DA UFMS/CPNV, 10., "História do livro, da leitura e das práticas escolares na educação brasileira: os desafios do tempo presente". Organizadores G. F. Bezerra, J. H. Prado e S. Matias, S. 2018. Naviraí. Anais [...]. Naviraí, MS, 2018. p. 1.004-1.013. ISSN 2178-2431. Disponível em: https://jornadaeducacaonavirai.ufms.br/files/2018/06/ANAIS_2018_X-JORNADA-NAC-EDU_Final.pdf. Acesso em: 9 fev. 2019. OLIVEIRA, E. A. História dos Terena da Aldeia Buriti: memórias, rituais, educação e luta pela terra. 2013. 103f. Dissertação (Mestrado em História) - Faculdade de Ciências Humanas, Universidade Federal da Grande Dourados, UFGD, Dourados, 2013.

SOBRINHO, R. S. M. Os saberes da "escola do branco" e as culturas das crianças indígenas uma prática pedagógica dos (des)encontros. In: NASCIMENTO, Adir Casaro; AGUILERA URQUIZA, Antonio Hilário; VIEIRA, Carlos Magno Naglis (org.). Criança indígena: diversidade cultural, educação e representações sociais. Brasília: Liber Livros, 2011.

VIEIRA, D. da S. Crianças indígenas na cidade: a educação infantil no Centro Social Mitangue-Nhiri. In: SEMINÁRIO DE CIÊNCIAS SOCIAIS, 10., Tecendo diálogos sobre a pesquisa social. 2012, Maringá. Anais [...]. Maringá: Universidade Estadual de Maringá; Departamento de Ciências Sociais, 2012. 